\title{
Ter liberdade é ganhar a guerra: Entrevista a Shahd Wadi
}

\author{
Having freedom is winning the war: Interview with Shahd Wadi \\ Tener libertad es ganar la guerra: Entrevista con Shahd Wadi
}

Helena Ferreira ${ }^{1}$

\begin{abstract}
Resumo: O objetivo desta entrevista a Shahd Wadi é dar voz a alguém que vive a história da Palestina no próprio corpo. Os discursos hegemónicos sobre a história da questão palestiniana/israelita estão repletos de esquecimentos, enganos, erros, e, até falsidades, que são os pilares de uma pseudo-história que se quer apresentar como realidade, quando quase nada ocorreu conforme o contam. Como forma de luta contra essa quase anti-história, dá-se aqui conta das relações de poder que envolvem todos os sistemas e estruturas opressoras e oprimidas.
\end{abstract}

Palavras-chave: Shahd Wadi; Palestina; Israel; colonização; apartheid; genocídio étnico.

Abstract: The purpose of this interview with Shahd Wadi is to give a voice to someone who lives the history of Palestine in his own body. The hegemonic discourses on the history of the Palestinian/Israeli question are full of oversights, mistakes, errors, and even falsehoods, which are the pillars of a pseudo-history that wants to present itself as reality, when almost nothing happened as they are told. As a form of struggle against this quasi anti-history, one can see here the power relations that involve all oppressive and oppressed systems and structures.

Key Words: Shahd Wadi; Palestine; Israel; colonization; apartheid; ethnic genocide.

Resumen: El propósito de esta entrevista con Shahd Wadi es dar voz a quien vive la historia de Palestina en su propio cuerpo. Los discursos hegemónicos sobre la historia de la cuestión palestino / israelí están llenos de descuidos, equivocaciones, errores e incluso falsedades, que son los pilares de una pseudohistoria que quiere presentarse como realidad, cuando casi nada sucedió como se cuenta. . Como forma de lucha contra esta cuasi antihistoria, se pueden ver aquí las relaciones de poder que involucran a todos los sistemas y estructuras opresivos y oprimidos.

Palabras Clave: Shahd Wadi; Palestina; Israel; colonización; segregación racial; genocidio étnico.

\footnotetext{
${ }^{1}$ Doutoranda do programa doutoral em Estudos Culturais da Universidade de Aveiro/Portugal e membro do grupo de Género e Performance do Centro de Línguas, Literaturas e Culturas da mesma Universidade.
} 
Shahd Wadi identifica-se como mulher palestiniana, entre outras possibilidades, porque defende que a liberdade, que é o seu maior apanágio, é sobretudo palestiniana. Sendo descendente de refugiados palestinianos, nasceu no Egipto, viveu a infância e uma boa parte da juventude na Jordânia e vive em Portugal desde 2006. É autora da primeira tese de Mestrado em Estudos Feministas em Portugal, apresentada na Universidade de Coimbra, com o título "Feminismos de corpos ocupados: as mulheres palestinianas entre duas resistências" $(2010)^{2}$ e da primeira tese de doutoramento, na referida área, apresentada na mesma Universidade e publicada com o título "Corpos na trouxa: histórias-artísticas-de-vida de mulheres palestinianas no exílio" (2017) ${ }^{3}$. No decorrer do seu doutoramento foi selecionada para a plataforma Best Young Researchers. Nessa investigação aborda as histórias de vida das mulheres palestinianas no exílio contadas através da sua arte e dos seus próprios corpos, incluindo o seu.

É ativista dos direitos humanos e do povo palestiniano e foi assessora para os assuntos culturais e imprensa da Missão Diplomática da Palestina em Portugal, durante onze anos, até ter sido demitida em julho deste mesmo ano, por motivos políticos.

Desde 2017 que a Shahd Wadi desata a sua trouxa palestiniana e feminista, através da sua obra e das várias palestras e debates onde tem participado, para contar a sua história e revelar o seu sonho: regressar a uma Palestina livre de todas as opressões. Tenho recebido essa partilha sempre que me é possível e assimilado uma nova redefinição dos conceitos de colonização, de apartheid e de genocídio étnico.

A conversa aqui reproduzida data de setembro de 2021.

\footnotetext{
${ }^{2}$ Shahd Wadi, "Feminismos de corpos ocupados: as mulheres palestinianas entre duas resistências" (Dissertação de Mestrado, Faculdade de Letras da Universidade de Coimbra, 2009), 87, https://eg.uc.pt/bitstream/10316/13354/1/Tese_mestrado_Shahd\%20Wadi.pdf.

${ }^{3}$ Shahd Wadi, Corpos na Trouxa: Histórias-artísticas-de-vida de mulheres palestinianas no exílio (Coimbra: Edições Almedina, S.A., 2017).
} 


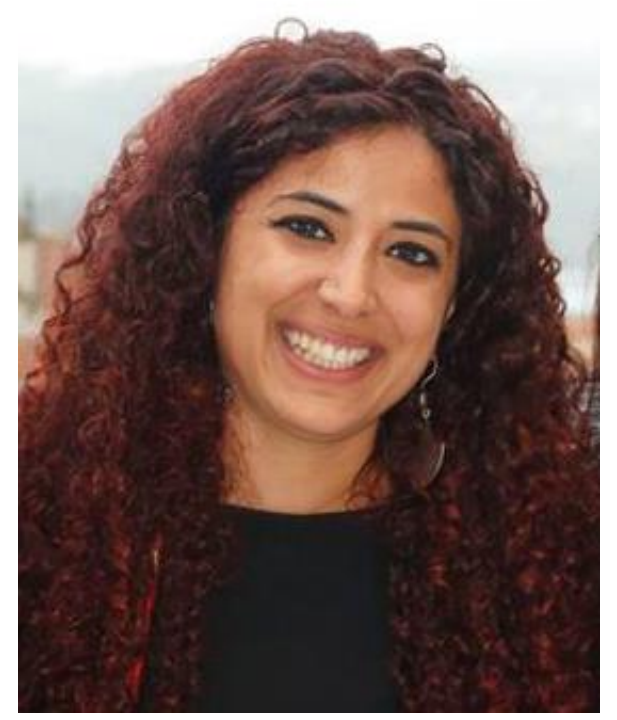

(Imagem 1: Shahd Wadi)

\section{Helena Ferreira (HF): Só faz sentido começar esta conversa pelo ano a que chamas "o ano zero no contexto palestiniano", o ano da Nakba, em 1948, que foi o ponto de partida quer para o exílio de muitas famílias, incluindo a tua, quer para a vida sob a ocupação de tantas outras famílias palestinianas. É aqui que tem início a tua história palestiniana e que se começa a construir uma nova história para a Palestina. Queres contextu- alizar?}

Shahd Wadi: A Nakba é um termo em árabe que significa "catástrofe" ou “desastre" e é utilizado, sobretudo, para referir a ocupação da Palestina e a expulsão do povo palestiniano através de um plano premeditado, cuja implantação continua até hoje. O objetivo deste plano é estabelecer um estado israelita exclusivamente judeu, o que implica uma limpeza étnica. Através do dia da Nakba, que normalmente é comemorado a 15 de maio, lembramos os cerca de 30 massacres e as 530 vilas e cidades (aproximadamente) que foram apagadas do mapa, incluindo a minha vila, a vila da minha família, dos meus

\footnotetext{
${ }^{4}$ Shahd Wadi, "Corpos na Trouxa: Histórias-artísticas-de-vida de mulheres palestinianas no exílio”, Cassandra, acesso em 22 de agosto, 2021, https://www.cassandra.pt/heroides-arquivo-vivo/corpos-na-trouxa.
} 
avós, de onde foram expulsas cerca de 800000 pessoas $^{5}$, que até hoje são refugiadas. O termo Nakba normalmente é atribuído ao sírio Constantin $\mathrm{Zu}-$ reiq, que escreveu o ensaio Ma’na Al-Nakba (O Significado do desastre) em 1948. Todavia, o termo Nakba foi mencionado pela primeira vez num dos folhetos que a força aérea israelita lançava sobre as populações da Palestina nas vésperas dos ataques às vilas e aldeias. Os folhetos funcionavam como uma ameaça, convidando o povo a render-se e a sair pacificamente para evitar uma Nakba. Os próprios agressores consideravam a destruição e expulsão como uma Nakba. ${ }^{6}$ E é por isso que o meu livro e tudo o que eu escrevo, de uma forma ou outra, começaram a ser escritos em 1948, muito antes de eu nascer. A vida de qualquer pessoa palestiniana começa nesse ano, independentemente do ano de nascimento dessa pessoa. É o ano zero, no contexto palestiniano, o ano de partida para o exílio ou o ano do início da vida sob ocupação.

HF: Penso ainda que temos de recuar no tempo, porque a frase "uma terra sem povo para um povo sem terra" é atribuída ao movimento que defende que os territórios da Palestina não eram ocupados. Temos, por isso, que fazer uma retrospetiva histórica da Palestina e do seu território. Podes fazer isso?

SW: O slogan "uma terra sem povo para um povo sem terra" já tinha sido utilizado antes da sua adoção pelo movimento sionista, e há várias interpretações desta frase. Alguns historiadores acreditam que fazia parte da propaganda israelita, que queria fazer acreditar que não havia lá um povo, o que confirma a existência de um plano de limpeza étnica ou daquilo que foi designado por "plano de transferência" (eufemismo sionista para a limpeza étnica realizada), para criar um estado exclusivamente judeu. O historiador Nur Masalha refere na sua obra "Palestine: a Four Thousand Year History", que

\footnotetext{
5 Segundo os dados, a Palestina possuía cerca de 1 milhão e 400 mil habitantes.

6 Shahd Wadi. "Nakba", Dicionário Alice, acesso em 22 agosto, 2021, https://alice.ces.uc.pt/dictionary/?id=23838\&pag=23918\&id_lingua=1\&entry=24419.

${ }^{7}$ Nur Masalha. Palestine: a Four Thousand Year History (Londres: Zed Books, 2020).
} 
o sionismo está muito ligado ao colonialismo europeu que ignorava completamente os direitos dos povos indígenas. O termo terra nullius, usado durante o colonialismo, não significava propriamente terra que não tem povo, mas que era uma terra que não estava a ser colonizada por nenhum estado europeu e, portanto, este slogan completamente racista vai no mesmo sentido da supremacia do colonialismo europeu, ou seja, neste caso significa que o povo palestiniano não conta, os palestinianos e palestinianas não são vistas como pessoas, não são seres humanos.

O movimento sionista foi criado no final do século XIX com o objetivo de criar um estado judeu na terra da Palestina através da colonização. Deve-se a Theodor Herzl, considerado o "pai do movimento sionista" a ideia de criar este estado. Existiam várias possibilidades para o lugar onde este estado poderia ser criado. Alguns historiadores apontam para: Argentina, Uganda, Chipre ou a Palestina, tendo isto sido discutido no I Congresso Sionista, em 1897, em Basileia, na Suíça. Posteriormente, foi enviada uma delegação à Palestina, para estudar o território, que depois de estar no terreno enviou a seguinte mensagem: “A noiva é bonita, mas é casada com outro homem”, ou seja, já havia um povo nesta terra. Apesar disso, em 1882, iniciaram-se várias vagas de emigração de judeus para a Palestina e, a partir daí começou a resistência palestiniana. Aliás, a primeira menção da participação das mulheres palestinianas fora do lar num ato de resistência é de 1884, que não sendo uma data certa é a indicada como o início da participação das mulheres na resistência. A Palestina estava sob o domínio do império Otomano desde o século XVI e juntou-se à Grã-Bretanha para derrotar os Otomanos, com a promessa que seria um Estado livre e assim ficou sob o mandato britânico desde 1920 (consoante o acordo Sykes-Picot). No entanto, a Grã-Bretanha também prometeu o mesmo aos judeus através da Declaração Balfour de 1917, onde anunciou a decisão de apoiar a criação de um estado judeu na terra da Palestina enviando uma carta à família do banqueiro Walter Rothschild, que investiu em territórios para os judeus que quisessem ir para a Palestina. A luta nacional Palestiniana começou a ser mais organizada a partir de 1920, data em que tiveram 
início os primeiros movimentos organizados por mulheres. $\mathrm{O}$ movimento sionista na Palestina era altamente militarizado através do Stern Gang, Irgun e Haganah e quando não conseguiram comprar mais do que 5\% dos territórios e perceberam que os palestinianos não tinham força militar, começaram a cometer os ataques terroristas como o atentado ao Hotel King David que acolhia funcionários do governo britânico, em 1946. Depois disso, em 1947, as Nações Unidas emitiram a resolução da partilha da Palestina em dois estados, recomendando que 56\% do território fosse destinado aos emigrantes judeus, que eram apenas $30 \%$ da população. A resolução foi votada, mas não foi implementada, o que deu espaço para o "plano de transferência" que já falamos, através do plano Dalet, que é um plano militar que iniciou a criação do Estado de Israel em 1948, logo depois da Grã-Bretanha se retirar. Neste ano foram expulsos mais de dois terços da população palestiniana e é esta geração da Nakba, principalmente as mulheres, que mantém a ideia da Palestina viva, transmitindo de geração em geração as histórias de vida sobre o que aconteceu na Nakba.

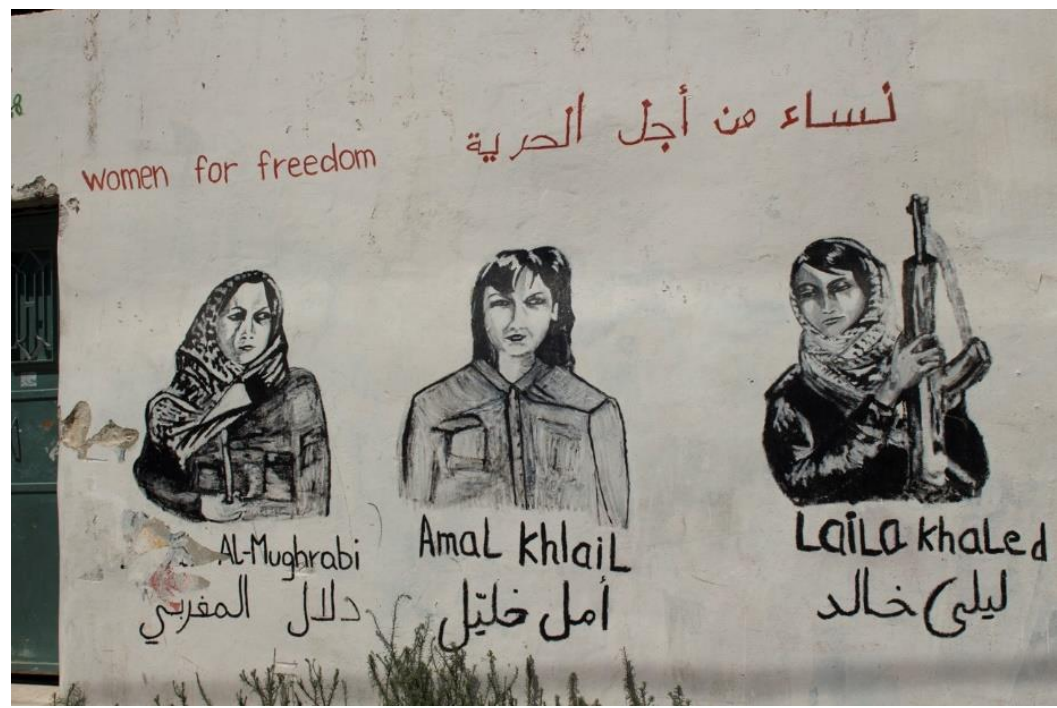

[Imagem 2: Mural no Campo de Refugiados de Aida (Foto de Shahd Wadi)]

HF: Pisaste o solo da Palestina pela primeira vez com 15 anos. $O$ que sentiste neste primeiro contato com a terra que te ensinaram a sentir como a tua terra? 
SW: Como escrevi no meu livro "Corpos na Trouxa"8: "Durante o meu primeiro regresso a uma terra que nunca conheci, tive a oportunidade de visitar uma vila de uma amiga muito perto da Ramallah. Khalto Ansaf apontou para uma montanha ao fundo mostrando-me a minha vila, al-Muzayri'a, e disseme: "a tua vila é o início da 'fronteira deles'. Aquela vila que nunca vi, mas sempre tinha sonhado abraçar como minha, estava lá. "Lá" estava muito perto para quem passou a vida a ver al-Muzayri'a em abstrato. Do nosso lado saiu um carro de um colonato buzinando, como um berro, a avisar que a nossa existência perturba os colonos. O carro passou ao meu lado e dirigiu-se para minha al-Muzayri'a. Enquanto eu me deixei ficar onde estava. Naquele momento e com o corpo paralisado, consegui, sim, passar a fronteira e chegar à minha vila, mesmo estando paralisada. Percebi, senti e decidi: sou palestiniana. No meu primeiro regresso a uma terra que nunca conheci, fiz uma visita ilegal, mas que defendo ser direito meu, ao mar de Haifa ocupado em 1948, o mar de onde vem a chuva do meu pai, a chuva-como-nenhuma-chuva. Senti as ondas roubadas pela ocupação a apertar o meu corpo pela primeira e muito provavelmente pela última vez, e senti o sangue a escorregar por entre as minhas pernas. Não foi a primeira vez que vi sangue a sair de mim, já me tinham dito há alguns anos que me tinha tornado uma mulher, mas foi só naquele momento que senti o mar e o sangue, e percebi, senti e decidi: um corpo.

Em 1998, cinquenta anos após a Nakba, numa montanha ao pé de al-Muzayri'a e num mar que manda o seu perfume para a minha vila, senti a Nakba que o meu corpo carrega numa trouxa. A Nakba estava adormecida num corpo carregado de memórias e cicatrizes do exílio. Um corpo numa trouxa cheia de saudades de uma casa que nunca conheceu: a Palestina. A minha relação com a Palestina é uma relação corporal, foi o quase-encontro do meu corpo com al-Muzayri'a e com o seu mar que me fez entender que este encontro ainda não se realizou. Numa terra e num mar que sempre me pertenceram e nunca me pertenceram, tornei-me um corpo palestiniano."

\footnotetext{
${ }^{8}$ Shahd Wadi, Corpos na Trouxa: Histórias-artísticas-de-vida de mulheres palestinianas no exílio (Coimbra: Edições Almedina, S.A., 2017), 17.
} 


\title{
HF: Vou ler um excerto de "Na presença da ausência" de Mahmoud Dar- wich':
}

\author{
"Perguntas: o que significa "refugiado"? \\ Dir-te-ão: É aquele que é arrancado da sua pátria. \\ Perguntas: O que significa "pátria"? \\ Dir-te-ão: A casa, a amoreira, o galinheiro, a colmeia, o cheiro do pão \\ e o primeiro céu. \\ Perguntas: Numa palavra tão pequena cabe tudo isso mas não cabemos \\ nós?"
}

\section{Já tentaste responder a esta pergunta?}

SW: Estamos a tentar desde 1948. Tudo o que eu faço é tentar responder a esta pergunta. O que é a pátria e como podemos "acontecer" nela. A minha constante procura de uma resposta parte também de outro verso de Mahmoud Darwich:

\footnotetext{
"Ah a minha ferida teimosa

A minha pátria não é uma mala

Eu não sou um viajante".
}

Mesmo que, na situação do exílio, a Palestina pareça uma mala, este não é o seu destino, segundo o poeta. Em vez de mala eu falo da trouxa, mas como Mahmoud Darwich, nego e ao mesmo tempo afirmo: a Palestina é uma “trouxa”. É uma pergunta constante: Será que a Palestina existe apenas na trouxa? Ou será que as trouxas da Palestina estão abertas a outras possibilidades?

A minha pátria que está dentro da trouxa, apesar de eu recusar que a minha pátria esteja só nessa trouxa. Não caibo na trouxa e ao mesmo tempo cabemos todas, nós e as nossas histórias, por isso é preciso abri-la para o mundo.

Como Mahmoud Darwich diz, a minha pátria também é uma amoreira. A história da minha família está ligada a uma amoreira, pode parecer que não cabemos nesta pátria, mas todos nós cabemos na memória de uma amoreira que

\footnotetext{
${ }^{9}$ Mahmoud Darwich, Na Presença da Ausência (Porto: Flâneur, 2018), 37.
} 
se lembra de nós. O meu tio nasceu e cresceu em Al-Muzayri’a antes do exilio. Cinquenta anos depois decidiu pedir autorização para poder ir à nossa vila, quando chegou estava quase a não conseguir reconhecer a nossa vila, mas sem mapas, sem indicações, sem referências ele conseguiu chegar, porque a sua amoreira estava lá à espera para lhe mostrar o caminho e falar-lhe sobre a sua solidão, sobre ter ficado sozinha naquela vila sem ele, que a tinha plantado. Ser uma pessoa palestiniana exilada significa saber que haverá sempre uma amoreira à nossa espera, para cabermos dentro dela. Nós estamos dentro da memória de cada amoreira da Palestina à nossa espera, que só existe para se lembrar de nós.

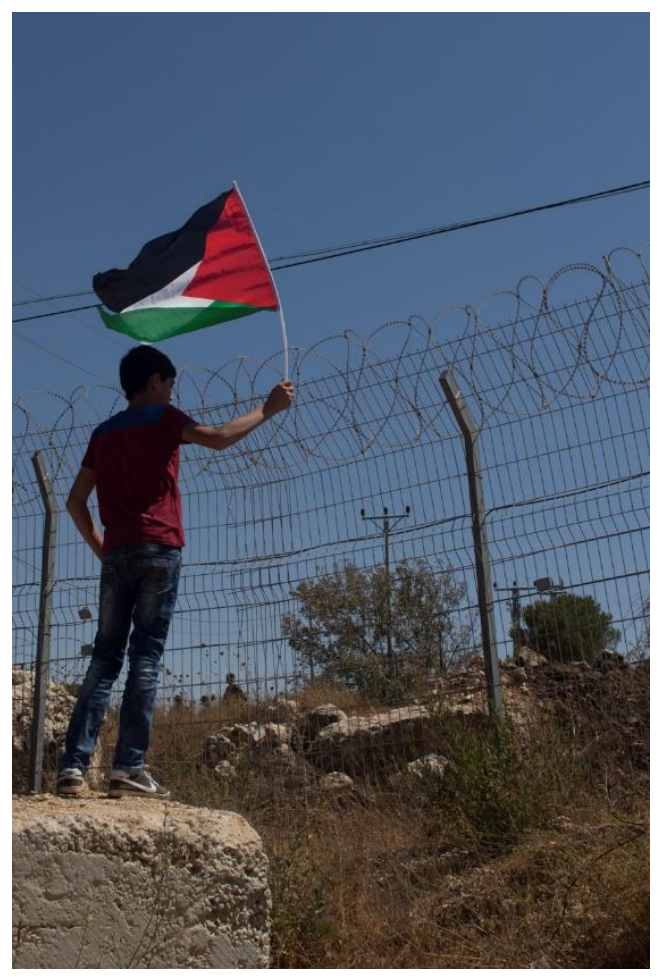

[Imagem 3: Criança com bandeira da Palestina a observar as árvores do outro lado da cerca com arame farpado (Foto de Shahd Wadi)]

\section{HF: Afirmaste que "A Palestina está em todo o lado. Como perdemos a terra, recuperámo-la em qualquer sítio."10 Nesta Palestina que encontras fora dos territórios palestinianos sentes-te em casa? Esta pergunta é uma}

\footnotetext{
${ }^{10}$ Maria João Lopes, "Shahd Wadi queria poder chamar feministas às palestinianas", Público online, acesso em 19 de agosto, 2021, https://www.publico.pt/2010/04/08/jornal/shahd-wadi-queria-poder-chamar-feministas-as-palestinianas$\underline{19120272}$
} 
tentativa de perceber se existe uma associação entre pátria - país de origem - casa, no sentido de lar... Como o sentes tu?

SW: O meu lar é a fronteira. A fronteira entre a Palestina e Portugal e todos os outros países pelos quais passei. Eu não tenho um lar de onde sou, é um processo. O lugar em que me sinto confortável é a fronteira, de alguma forma encontrei a Palestina também aqui em Portugal, através da minha investigação e da minha escrita. Foi nas palavras que encontrei a Palestina, um lugar que é muito parecido com o lugar que poderia ser o meu. Portanto, acho que o meu lar fisicamente não existe, mas existe de uma forma imaginada. Existe na escrita, nas palavras. Existe no constante desejo de regresso. Quando estava a escrever a tese pensava: "Será que nenhum lugar me pertence? Será que eu sou sempre a estrangeira? Será que sou eternamente a Outra?” E, esta escrita fez-me regressar à Palestina e senti-me em casa.

HF: A chave é um símbolo de resistência dos palestinianos que foram expulsos das suas casas e do seu país. Muitos ainda guardam as chaves das portas das entradas principais das suas casas, porque consideram que este é o único legado que têm para deixar aos seus filhos. A tua família ainda guarda as chaves da vossa casa?

SW: Coleciono chaves e todas as pessoas que sabem da história das chaves da Palestina oferecem-me chaves. Tenho uma parede cheia de chaves. Mas não sei onde está a chave da nossa casa em Al-Muzayri'a. Todavia, tenho um objeto que considero a minha chave. É o escorredor da minha avó que está na minha casa em Lisboa. Este escorredor que tenho na minha sala tem um fio, que os meus pais me disseram para não tirar, porque tinha sido posto pela minha avó, para o poder pendurar. Eu sinto uma enorme responsabilidade, por ter este escorredor comigo. Outro objeto que está na casa dos meus pais é o cartão de refugiado do meu avô, que contém o número da nossa vila e, portanto, este cartão prova que eu sou palestiniana, que sou descendente de refugiados e que tenho o direito de voltar lá. Este cartão do meu avô tem buracos. 
Cada vez que ele ia buscar ajuda alimentar, faziam-lhe um buraco no cartão. Quando escrevi o meu livro referi que meu corpo palestiniano exilado está também marcado por estes buracos que marcam a minha memória herdada e a minha vontade de regressar à Palestina. Quando, mais tarde, recebi o escorredor vi que este também tem buracos como o cartão, os mesmos buracos que estão dentro do meu corpo e que me dão esta enorme vontade de devolver o escorredor ao seu lugar, um dia.

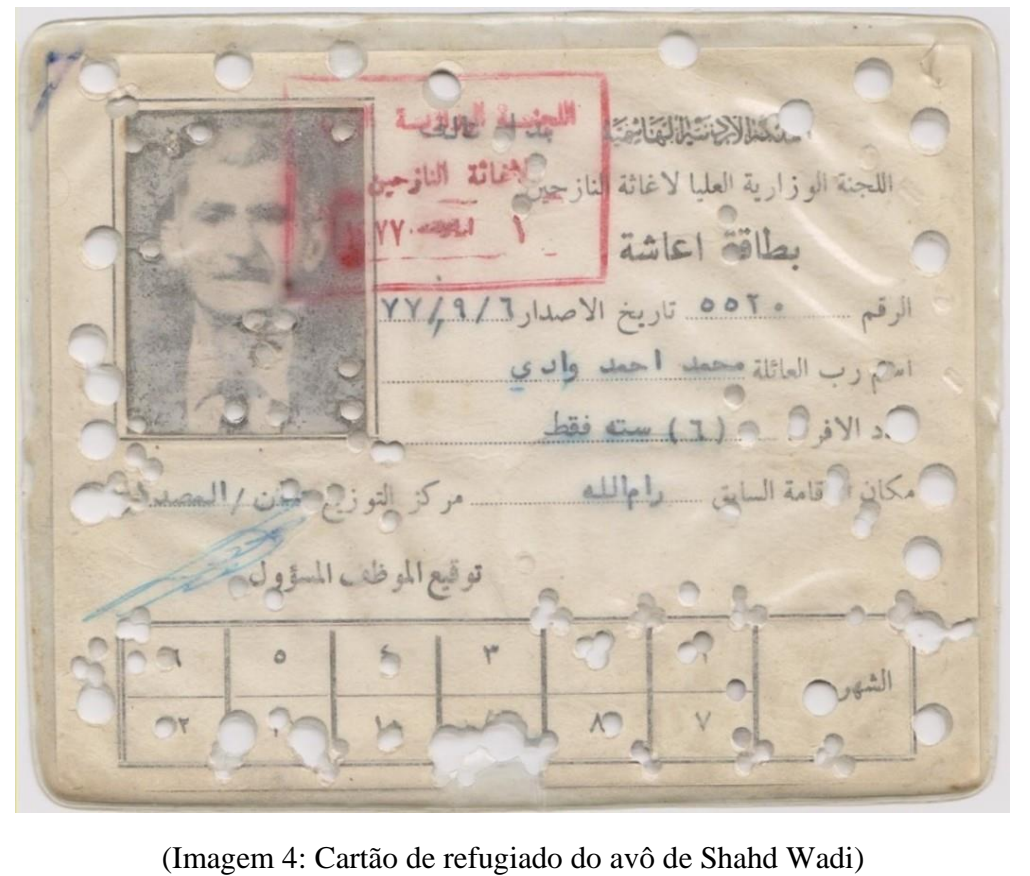

\section{HF: Como defines o que se passa entre Palestina/Israel? Sei que na tua obra falavas em "conflito", mas presentemente consideras que esse termo não é o mais correto. Quais os termos que consideras mais significativos para designar o que se passa entre os dois países e porquê?}

SW: Na verdade, no "Corpos na trouxa" utilizo muito pontualmente a palavra "conflito", mas, como tudo é um processo, deixei de a utilizar, porque quando existe uma ocupação não se pode falar de dois lados e para que exista um conflito é necessário que existam dois lados. Dois lados com forças. Neste caso, temos um ocupado e um ocupante, um oprimido e um opressor e, portanto, há uma ocupação, não há um conflito. O que se passa na Palestina é o 
settler colonialism, que algumas pessoas traduzem para "colonialismo da ocupação", que é um tipo de ocupação que tem como objetivo não só anexar os territórios, mas substituir os habitantes através de um plano de limpeza étnica. E é muito importante utilizar este termo, como também é importante utilizar o termo apartheid, não apenas como analogia ao que aconteceu na Africa do Sul, mas como um termo legal, porque legalmente, consoante as definições do Estatuto de Roma do Tribunal Penal Internacional, o que está a acontecer na Palestina é apartheid. Foi este o termo que a Human Rights Watch ${ }^{11}$ utilizou, porque legalmente o que está a acontecer é apartheid. Não se trata de uma analogia com a África do Sul, muito embora a luta deste país nos inspire, é importante dizer que não é algo metafórico, é algo bem real, que se encontra definido legalmente.

HF: Saleh Abdel Jawad considera que o termo certo é sociocídio "que significa a destruição total dos palestinianos, não apenas como entidade política ou grupo político nacional, mas como sociedade. $O$ objetivo final é a expulsão dos palestinianos da sua terra natal (isto é, limpeza étnica total ou em grande escala)" ${ }^{12}$. Ilan Pappé $(2016)^{13}$ diz que sim, que se trata de uma limpeza étnica definindo-a como "um esforço para deixar homogêneo um país de etnias mistas, expulsando e transformando em refugiados um determinado grupo de pessoas, enquanto se destroem os lares dos quais elas foram enxotadas. [...] Os massacres acompanham as operações, mas, quando acontecem, não são parte de um plano genocida, mas sim uma tática crucial para acelerar a fuga da população marcada para expulsão. Mais tarde, os expulsos são apagados da história oficial e popular do país e extirpados da memória coletiva". Concordas com estes termos tão fortes? Consideras importante fazer uso desta linguagem para fazer entender o que se passa no médio oriente?

\footnotetext{
${ }^{11}$ Human Rights Watch, "A Threshold Crossed Israeli Authorities and the Crimes of Apartheid and Persecution", Human Rights Watch, acesso em 19 de agosto, 2021, https://www.hrw.org/report/2021/04/27/threshold-crossed/israeli-authorities-and-crimes-apartheid-and-persecution.

${ }^{12}$ Saleh Abdel Jawad, "La política israelí hacia el Pueblo palestino: un "sociocidio", Viento Sur (2006): 15.

${ }^{13}$ Ilan Pappé, A limpeza étnica da Palestina (São Paulo: Sundermann, 2016). p. 23.
} 
SW: Não são termos fortes. Tal como já referi, não são analogias. As definições legais de limpeza étnica, apartheid e genocídio aplicam-se totalmente ao que está a acontecer na Palestina.

\section{HF: Para lutar contra o sociocídio foi criado o movimento BDS (Boicote, Desinvestimento e Sanções) com o objetivo de pressionar Israel a respei- tar os direitos do povo palestiniano. Podes explicar este movimento?}

SW: A sociedade civil palestiniana, bem como numerosas organizações internacionais defenderam que, perante a incompetência dos órgãos internacionais e a conivência dos governos de diferentes países, apenas uma política e um plano internacional de pressão, a longo prazo, sobre Israel, seria capaz de levar ao fim da ocupação. O Movimento de Boicote, Desinvestimento e Sanções (BDS) iniciou-se em 2005 em resposta ao apelo lançado pela sociedade civil palestiniana e coordenado pelo Comité Nacional BDS Palestiniano (BNC). Inspirado na campanha internacional que ajudou a derrotar o regime de apartheid na África do Sul, tem como objetivo isolar e pressionar Israel para que cumpra a lei internacional e os direitos do povo palestiniano. Pretende acabar definitivamente com a ocupação e colonização dos territórios palestinianos ocupados, desmantelar o muro da separação racista, garantir direitos iguais para os palestinianos dentro de Israel, e respeitar e proteger o direito do regresso dos refugiados palestinianos.

Existe uma campanha específica de boicote académico e cultural, um dos alvos do boicote são as universidades israelitas por causa do seu papel enquanto colaboradoras do exército, fomentadoras do branqueamento da imagem de Israel, para além dos casos mais óbvios de universidades construídas em territórios ocupados.

Como bem notam as associações feministas e queer palestinianas, a ocupação israelita não só atinge todas as pessoas palestinianas como também cimenta 
estruturas patriarcais dentro da própria sociedade palestiniana. Por isso, muitos departamentos de Estudos de Género, tal como muitas feministas de renome responderam ao apelo de boicote cultural e académico, tais como: Judith Butler, Joan Scott, Angela Davis, Alice Walker, Sarah Schulman, Arundhati Roy, Naomi Klein, entre outros, confirmando a interseccionalidade de sua luta e levantando o slogan: BDS é uma questão feminista.

HF: Como é que explicas que, contrariamente ao que aconteceu nos anos oitenta, na campanha de boicote sul-africana contra o apartheid, este movimento tenha tido tão pouca aderência por parte do mundo ocidental e ter levado, muitas vezes, a acusações de antissemitismo a todos aqueles que, de algum modo, apoiaram o movimento? Sendo do conhecimento geral que a gestão biopolítica expressa que a ação governamental de Israel organiza, controla e administra as vidas palestinianas e decidiu que estes corpos não merecem atenção, proteção e cuidado, segundo o pensamento de Judith Butler ${ }^{14}$.

SW: Eu não acho que a campanha de Boicote, Desinvestimento e Sanções tenha menos impacto do que a campanha da Africa do Sul. Aliás, os dados referem que a campanha do BDS conseguiu em poucos anos muito mais que a campanha de boicote na Africa do Sul. Mas, quanto às acusações de antissemitismo, é evidente que são uma estratégia para silenciar este movimento. Esta acusação é em si antissemita, porque não reconhece a pluralidade dos judeus e assume que todos os judeus apoiam o Estado de Israel e, deste modo, atribuem a culpa dos crimes de Israel a todos os judeus. É importante também dizer que o movimento de Boicote, Desinvestimento e Sanções conta com o apoio de muitos judeus e, sobretudo, de movimentos especificamente judeus. O maior movimento de solidariedade com a Palestina nos Estados Unidos é o Jewish Voice for Peace, que é um movimento judeu, como diz o nome, contradizendo assim com a tática de equiparar a luta contra o sionismo ao antissemitismo. Muitos pensadores judeus (como Judith Butler, Noam Chomsky,

14 Judith Butler, Corpos que importam: Os limites discursivos do “sexo” (São Paulo: Crocodilo Edições, 2019). 
Ilan Pape, Naomi Klein, Norman Finkelstein, entre outros) apelam para uma distinção entre judaísmo e sionismo, reivindicando um espaço para pensadores judeus criticarem o estado de Israel. Importante ressaltar que o movimento BDS, que se define como intersecional, rejeita qualquer tipo de discriminação, incluindo, claro, o antissemitismo.

HF: Slavoj Žižek (2014) ${ }^{15}$ observa que, por vezes, a memória do Holocausto é instrumentalizada para justificar a fundação do Estado de Israel, o que é errado, porque "a única referência permitida ao Holocausto deveria ser uma referência negativa. O Holocausto não deveria ser evocado para justificar/legitimar quaisquer medidas políticas, mas apenas para deslegitimá-las (algumas delas), para impor certos limites aos nossos atos políticos: seria justificado condenarmos atos que manifestem uma hubris cuja expressão extrema foi o Holocausto". Parece-te uma explicação lógica, a de que a Europa, ao carregar a culpa do Holocausto, não queira, de modo nenhum, interferir com o Estado de Israel?

SW: Qualquer país que utiliza uma superioridade imaginada para oprimir outro povo deve ser julgado e Israel não pode ser exceção. Aliás, é importante que se diga que a Declaração de Balfour é, ela própria, antissemita, porque só ocorreu devido à elevada emigração de judeus que existia para a Inglaterra e para o resto da Europa, devido ao Holocausto. Queriam ver-se livres dos judeus na Europa. $\mathrm{O}$ pior que aconteceu aos palestinianos foi sofrerem às mãos daqueles que sofreram algo muito semelhante. Quando se fala em Holocausto, não podemos esquecer a Nakba. E esse é o papel da Europa. Nenhum país deve ficar impune, só porque foi vítima às mãos de outro povo. E, devem ser questionados pelos atos que cometem no presente e julgados pelos seus crimes.

HF: Nelson Mandela como figura carismática, visto como um herói por muitos, também contribuiu para que a campanha de boicote ao

15 Slavoj Žižek, Violência: seis reflexões laterais (São Paulo: Boitempo, 2014), p.97. 
apartheid da Africa do Sul tivesse muitos apoios. Talvez falte essa figura à Palestina, ou talvez o ocidente não esteja preparado para ver carisma e heróis no Outro oriental islâmico (Said, 1978, 1979) ${ }^{1617}$. Podes falar-nos de algumas figuras da referência palestiniana?

SW: As figuras que eu admiro hoje não têm nome, não são pessoas conhecidas. São uma geração nova que está a resistir, são as pessoas de Sheikh Jarrah, de Beita, de Gaza, de Nazaré e de todas as terras palestinianas. É nelas que eu acredito hoje, nestas pessoas que são anónimas, que não são conhecidas para o mundo. Muitas mulheres jovens também, que vimos ultimamente a liderar as manifestações. Eu não sei mexer no Instagram, mas vi-me obrigada a utilizá-lo para poder seguir estas pessoas, especialmente as mulheres jovens que me inspiram, como por exemplo Muna El-kurd ${ }^{18}$. Os quatro prisioneiros políticos palestinianos que reconquistaram por alguns dias a sua liberdade escapando da prisão Gilboa ${ }^{19}$ também são, sem dúvida, os nossos Mandelas. Também não podemos esquecer os discursos e poemas da mãe de Mahmoud AlArda (um destes prisioneiros), que nos inspirou apesar do seu nome ter ficado desconhecido. Estas são as figuras de referência, são os "Nelson Mandelas" que ainda são poucas conhecidas.

HF: Enquanto investigadora dedicas-te mais ao estudo das vidas e dos corpos das mulheres nascidas e educadas no exílio, às que vivem nas fronteiras (Anzaldúa, 1980) ${ }^{20}$. Mas, não posso deixar de fazer esta pergunta: Como é a vida dos palestinianos atualmente nos territórios ocupados da Palestina? Em Gaza, que tantas vezes fica debaixo do fogo israelita? E nos campos de refugiados?

\footnotetext{
${ }^{16}$ Edward Said, Orientalism (New York: Vintage, 1978).

${ }^{17}$ Edward Said, The question of Palestine (New York, Vintage, 1979).

${ }^{18}$ Muna El-Kurd e o seu irmão Mohammed El-Kurd são ativistas palestinianos e foram considerados pela revista Time duas das 100 pessoas mais influentes de 2021.

${ }^{19}$ Fala de quatro dos seis palestinianos que escaparam da prisão de segurança máxima de Gilboa, depois de escavarem um túnel à mão, no início do mês de setembro e que foram capturados quatro dias depois.

${ }^{20}$ Gloria Anzaldua, Borderlands / La Frontera: The new mestiza (San Francisco: aunt lute books, 1980).
} 
SW: É muito difícil falar da Nação Palestiniana como se fosse uma. Cada realidade é uma realidade. As pessoas exiladas têm uma realidade, as da Cisjordânia outra, as que estão nos territórios ocupados desde 1948 têm outra realidade, e os que vivem em Gaza outra, ainda. Dentro de todas estas categorias há refugiados. Mesmo dentro dos territórios ocupados há refugiados, há quem tenha saído da sua terra para ir para a terra ao lado e nunca mais puderam voltar. Em Gaza, 80\% da população são refugiados. A realidade em Gaza é muito diferente de Cisjordânia, porque Gaza está quase a tornar-se num lugar inabitável. Recentemente estive a falar com europeus que trabalham na Palestina e que me disseram: “o que está a acontecer em Gaza está muito para além da imaginação humana". Posso falar sobre a falta de eletricidade, da água suja, dos bombardeamentos, e continuaria a ser injusta, porque não será suficiente, porque tudo o que acontece ali está muito além daquilo que qualquer ser humano possa compreender, se não o tiver vivido.

Isso é algo que Israel conseguiu: fragmentar este povo em várias realidades diferentes. E, quando se fala no que está a acontecer na Palestina, como é que vivem as pessoas palestinianas é preciso distinguir de que Palestina se está a falar. Apesar desta fragmentação, os últimos acontecimentos na Palestina, que se iniciaram em Sheikh Jarrah, mas que rapidamente se estenderam para Gaza, e para outros lugares como Jerusalém, Cisjordânia e para todo o lado, melhor dizendo, provaram que este povo é unido na resistência. Isto foi o mais bonito que aconteceu ultimamente, dizer a Israel que nos podem fragmentar e colocar em realidades completamente diferentes, mas nós continuamos juntos, unidos na resistência. E, foi muito bonito ver as manifestações acontecerem em simultâneo nos vários territórios que albergam o povo palestiniano, porque isso mostra que esta nação palestiniana, com realidades diferentes, continua a ser uma nação e a "resistência" é a palavra que a une. 


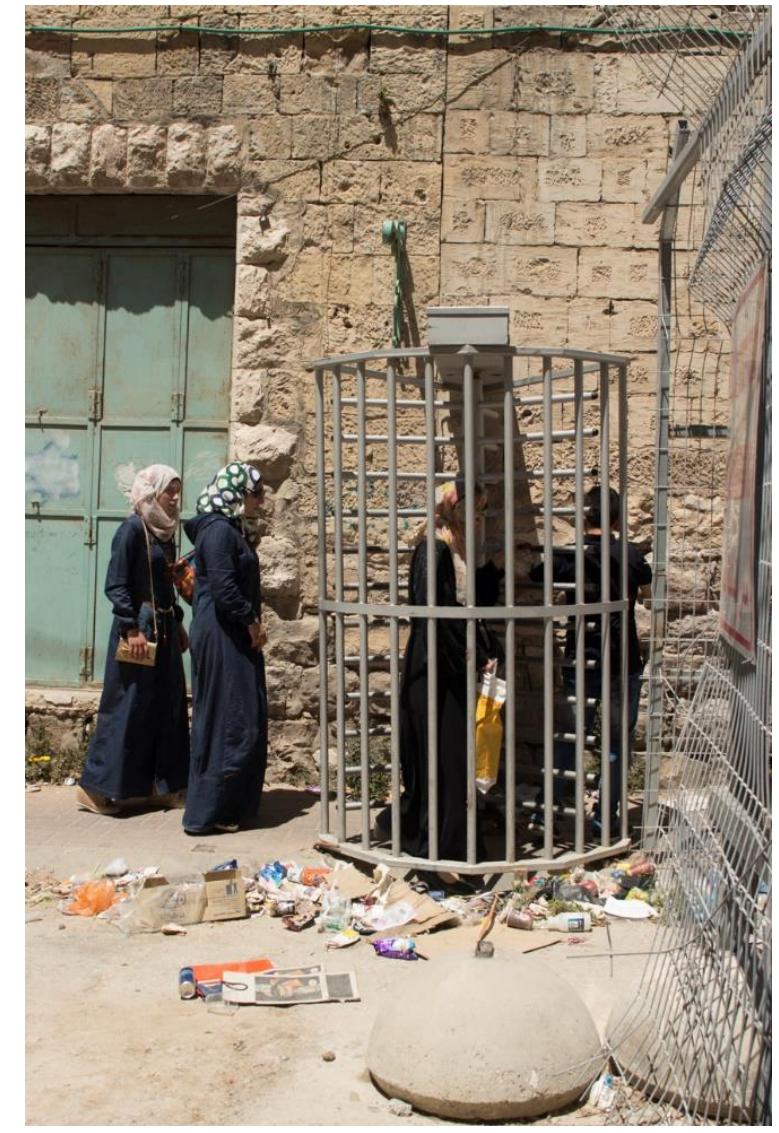

[Imagem 5: Posto de controlo em Hebron (Foto de Shahd Wadi)]

HF: "E, no entanto, nada existe no mundo que possa impedir o homem de sentir-se nascido para a liberdade. $O$ que quer que advenha, jamais ele poderá aceitar a servidão, pois nele existe o pensamento" (Weil, 2017) ${ }^{21}$. Simone Weil afirma que o ser humano jamais poderá deixar de sonhar com uma liberdade sem limites. Consideras que esse sonho é possível num território ocupado e controlado por soldados que fazem uso do poder e da força para desumanizar os corpos oprimidos?

SW: Essa é a única razão pela qual o povo palestiniano ainda existe. É nunca deixar de sonhar com essa liberdade. Se assim não fosse, há muito tempo que o povo palestiniano não existiria. Se eu acabei de dizer que o que acontece

\footnotetext{
${ }^{21}$ Simone Weil, Reflexões sobre as causas da liberdade e da opressão social (Lisboa: Antígona Editores Refratários, 2017), p.73.
} 
em Gaza está muito para além da imaginação humana, então o que faz sobreviver a Palestina? De onde vem esta resiliência? Este deixar-se ficar? Há uma palavra palestiniana que é uma das minhas palavras favoritas, al-Sumud, que é um tipo de resistência que tem a ver com o tempo. É um tipo de resistência de "deixar ficar", de resiliência de permanecer. Não vamos embora. Apesar de tudo, não vamos embora. E, não vamos desaparecer. Como Mahmoud Darwish diz, os palestinianos têm uma doença incurável, que se chama esperança. E é esta esperança e o sonho com essa liberdade que permitem que a Palestina permaneça viva e que os escritores palestinianos escrevam e as bailarinas palestinianas dancem... E que o mundo saiba que a Palestina existe e resiste. Este sonho está a fazer acontecer.

\section{HF: "Como distorção do ser mais, o ser menos leva os oprimidos, cedo ou tarde, a lutar contra quem os fez menos" (Freire, 1987) ${ }^{22}$. Isso tem acontecido com as intifadas. Dizes-nos o que é uma intifada situando-as no tempo, falando também das suas consequências.}

SW: As intifadas, tal como a Nakba e a $N k s a^{23}$ são movimentos históricos temporais muito importantes na vida dos palestinianos. Aliás, nós dizemos da geração da $N a k b a$, da geração da $N a k s a$, da geração da Intifada e, portanto, até as gerações na Palestina são marcadas por estes movimentos. "Intifada" é um verbo que significa "agitar-se”, especialmente o corpo. E, devo dizer que, para mim, é muito importante esta ideia da existência do corpo dentro desta palavra, porque é uma resistência que acontece através do corpo. São corpos que já não aguentam mais, portanto têm de se agitar, de se mexer. A primeira Intifada ocorreu em 1987 e a segunda Intifada ocorreu já depois dos Acordos de Oslo, em 2000, quando Ariel Sharon invadiu a Mesquita de Al-Aqsa escoltado por soldados israelitas, reivindicando tudo o que Israel não fez e de-

\footnotetext{
22 Paulo Freire, Pedagogia do Oprimido (Rio de Janeiro: Paz e Terra, 1987), p.20.

${ }^{23}$ Naksa ou "o dia do revés", refere-se ao dia em que dezenas de milhares de palestinianos foram deslocados das suas terras natais no final da Guerra dos Seis Dias, que teve início a 5 de junho de 1967.
} 
veria ter feito. Através das Intifadas conseguiu-se organizar o povo. Na primeira Intifada, especialmente, não havia qualquer tipo de organização e a partir daqui organizaram-se comités sociais, de educação, inclusive, foram fechadas as escolas pela ocupação e através da Intifada organizou-se uma forma de educação informal. Portanto, não era só uma luta contra a ocupação, era também uma luta por uma vida melhor. Serviu como organização da vida social e cultural dentro da Palestina. Os movimentos das mulheres ficaram muito mais organizados, muito mais fortes, porque existiam comités de mulheres dentro da Intifada que permaneceram até hoje. Esta ideia de a Intifada ser um símbolo, uma metáfora da resistência, poeticamente falando também mostra que as armas que a Palestina possui são as pessoas, são os seus corpos.

\section{HF: As mulheres palestinianas artistas que abordas na tua investigação contam, através da sua arte, a história do povo e do território palestini- ano e, como bem referes, "foram as responsáveis por manter a ideia da Palestina viva" (Wadi, 2017) ${ }^{24}$. Podes falar sobre algumas delas, situ- ando-as geograficamente e dando a conhecer as suas produções e as suas resistências?}

SW: Na minha investigação estudo a possibilidade de um ativismo político feminista através da narrativa do corpo em criações artísticos e culturais contemporâneos produzidos no exílio. Estudo artistas como Annemarie Jacir, realizadora do filme Melh hatha Al-Bahr (O Sal deste Mar) (2008), nasceu na Arábia Saudita, cresceu nos Estados Unidos e viveu na Jordânia e Palestina. Cherien Dabis, realizadora do filme Amreeka (2009), nasceu nos Estados Unidos e cresceu entre este país e a Jordânia. A poeta Suheir Hammad nasceu na Jordânia e cresceu nos Estados Unidos. A poeta Rafeef Ziadah nasceu no Líbano e viveu na Tunísia, Grécia, Estados Unidos, Canadá e Inglaterra. Leila Hourani, a autora do romance Bawh (Revelação) (2009), nasceu na Síria e

\footnotetext{
${ }^{24}$ Shahd Wadi, Corpos na Trouxa: Histórias-artísticas-de-vida de mulheres palestinianas no exílio (Coimbra: Edições Almedina, S.A., 2017), p. 21.
} 
viveu no Líbano, Chipre e Rússia. Huzama Habayeb, autora do romance $Q a$ bla an tanam Al-Malika (Antes que a rainha adormeça) (2011), nasceu no Kuwait e viveu também na Jordânia e nos Emirados Árabes Unidos. A artista Mona Hatoum nasceu no Líbano e foi re-exilada para Londres em 1975 após a guerra civil no Líbano, e viveu noutros países também como a Alemanha. A artista Raeda Saadeh e as cantoras hip-hop Safa Hathoot e Nahwa Abedelal, da banda Arapyat, e Abir Alzinaty, conhecida por Sabreena da Witch, são designadas como "exiladas em casa", ou "exiladas no seu país", pois fazem parte da população palestiniana que nasceu no que hoje se chama Israel, vivem lá e têm a cidadania israelita.

\section{HF: Ainda na tua obra comparas Israel ao macho "retrossexual" e a Pa- lestina a uma mulher. Podes explorar estes conceitos?}

SW: O discurso da ocupação Israelita e o discurso hegemónico palestiniano são ambos nacionalistas e recorrem a um certo tipo de discurso de masculinidade e de poder. Parece que há sempre uma competição simbólica de masculinidades entre o ocupante e o ocupado. Esta competição acontece utilizando os corpos das mulheres palestinianas. Por exemplo, há muitas obras artísticas icónicas de que falo na minha obra que estão ligadas a esta ideia de que os corpos das mulheres são corpos puros, férteis, são a paisagem da Palestina e existe uma narrativa sexualizada que aparece nos dois lados, sobretudo no discurso da ocupação. Por exemplo, os elementos do exército Israelita, através de fotografias nas redes sociais, apresentam-se como o homem modelo, forte, violento e retrossexual. É aí que eu utilizo esta imagem, este homem forte que luta contra o mal, a Palestina, que é uma mulher perigosa com o véu, que precisa ser dominada e disciplinada. O termo "retrossexual" é utilizado para denominar um homem com aparência de rude, de macho à antiga, que tem feridas de guerra e tem uma atitude também violenta. Esta pornografia bélica foi utilizada pelo exército Israelita para justificar a violência contra os palestinianos. Muitas artistas palestinianas fizeram uma reescrita desta representação. Afastam dos seus corpos uma posição colonial e patriarcal, mas 
mantêm uma ligação com a Palestina. Os próprios corpos destas mulheres tornam-se no meio para construir uma narrativa pessoal, que reflete a história coletiva da Palestina.

\section{HF: Terminas o teu livro falando em "regresso" e isso implica necessari- amente uma solução para o médio oriente. Qual poderia ser a melhor solução no teu ponto de vista? Porque, não posso deixar de me lembrar do título de Joan Margarit (2018) "Para ter casa há que ganhar a guerra". Terá de ser assim? Ou, como poderá isso ser se Israel é muito mais poderoso?}

SW: A solução tem de ser justa para todas as pessoas. Muitos discutem se a solução estará num estado ou em dois estados. E eu digo: Que tipo de Estado? Que tipo de dois Estados? Dois Estados independentes, democráticos e livres como, por exemplo, Portugal e Espanha, onde as pessoas circulam livremente e eu posso, sem qualquer problema, ir à minha terra? Ou um Estado onde todas as pessoas têm direitos e deveres iguais? Onde todos têm direito ao voto? Ou será um Estado de apartheid? É importante perguntar. Que tipo de um Estado? Que tipo de dois Estados? Sabendo da situação e das mudanças que aconteceram agora no terreno, a situação de dois Estados já não me parece viável. Não me parece possível. E, portanto, se temos esperança e se sonhamos, sonhamos com algo em que toda a gente poderá viver lá, no território, de forma igualitária e livre, onde todos têm direitos iguais, independentemente de quem são. É possível encontrar uma solução justa, mas o que é que é isso de ganhar a guerra? Como podemos definir "ganhar a guerra"? Isso poderá ser definido de várias maneiras, poderá ser, inclusive, conseguir um lugar justo, onde as pessoas vivem em igualdade e liberdade. E, quando falo em liberdade, falo em todo o tipo de liberdade, não é só a liberdade da ocupação. Isto é ganhar uma guerra, para mim. Ter liberdade é ganhar a guerra. $\mathrm{Na}$ Palestina e em qualquer parte do mundo. É preciso ganhar a guerra contra

25 Joan Margarit, Para tener casa hay que ganar la guerra (Barcelona: Austral, 2018). 
qualquer colonização, contra qualquer discriminação, contra qualquer desigualdade. Esta é a guerra que necessitamos ganhar. Contra todos os poderes instalados no mundo.

HF: Na tua opinião uma Palestina livre da opressão de Israel será uma Palestina livre de todas as opressões? Ou a luta contra o patriarcado farse-á mais tarde, como em todos os países da Europa que se assumem livres e democratas, e só é possível fazê-la quando o país não for uma colónia?

SW: É exatamente isso que acabei de dizer. Quando lutamos pela liberdade, lutamos por toda a liberdade. A liberdade não pode ser fragmentada. Eu quando me assumo como palestiniana, assumo-me também como feminista, porque para mim são inseparáveis. Quando estou a lutar pelas questões feministas estou a lutar contra o racismo, contra o antissemitismo, contra as alterações climáticas, contra a homofobia, estou a lutar contra todas as formas de opressão e injustiças. Por isso digo que sou palestiniana e feminista. Porque isso, para mim, quer dizer que sou uma pessoa que luta por todas as liberdades.

HF: Arundhati Roy $(2020)^{26}$ publicou agora um novo livro, "Azadi: Freedom. Fascism. Fiction". Azadi significa liberdade em urdu. A escritora escolheu-a porque durante cerca de trinta anos ela simbolizou a luta pela independência do povo da Caxemira e foi utilizada pelo movimento feminista indiano dos anos setenta e oitenta. Nesta obra, a autora aborda as complexidades das questões políticas e sociais da Índia e de Caxemira, que se agravaram com a pandemia e sugere que talvez o covid 19 tenha sido uma boa oportunidade para repensar o mundo em que vivemos, porque segundo ela nada seria pior do que um regresso àquilo que apelidávamos de normalidade. $O$ que pensas disto?

${ }^{26}$ Arundhati Roy, Azadi: Freedom. Fascism. Fiction (Chicago: Haymarket Books, 2020). 
SW: Eu não conheço o livro, mas vi um vídeo da Arundhati Roy durante a pandemia covid 19 que foi muito inspirador. Comecei, também, a ler o livro “O Futuro Começa Agora, Da Pandemia à Utopia”, do Boaventura de Sousa Santos $(2020)^{27}$ e ele também fala dessa questão, que a pandemia tem de ser uma oportunidade para a mudança, porque nos mostrou, de forma evidente, as desigualdades abissais que existem no mundo. Ele fala inclusive na Palestina e na Faixa de Gaza, em como a pandemia colocou a nu a pandemia da ocupação. Os primeiros casos de covid 19 na Palestina surgiram nos trabalhadores que trabalham em Israel, em condições degradantes. Aliás, basta pensar nisto, como é que Israel muito depressa vacinou quase todo o povo enquanto na Palestina não havia vacinas?

Num dos bombardeamentos, a primeira coisa que atingiram em Gaza foi o Centro de testes de covid. Vários presos palestinianos nas prisões israelitas foram infetados pelos soldados israelitas durante o interrogatório e nunca foram tratados e não tinham as mínimas condições de higiene. Tudo isto já existia, mas na Palestina como no resto do mundo, a pandemia fez-nos pensar e ver as coisas de uma forma muito evidente e clara. Digo no meu livro que o exílio é o início de um lugar de resistência e a pandemia e a sua maneira de exílio (confinamento) deve ser também um lugar de resistência, contra todas as desigualdades e deve-nos levar a repensar o mundo.

HF: Afirmas que um poema, um filme, uma fotografia, uma conversa no TedX, uma tese são as trouxas do exílio das mulheres palestinianas e é através da partilha dessas trouxas que tu e todas as mulheres palestinianas resistem e continuam a sonhar com o regresso a uma Palestina livre. Espero que esta entrevista tenha sido mais uma trouxa que desataste e um passo em frente na realização do teu sonho.

SW: Obrigada!

\footnotetext{
${ }^{27}$ Boaventura de Sousa Santos, O Futuro começa agora, da pandemia à utopia (Lisboa: Edições 70, 2020).
} 


\section{Referências Bibliográficas}

Anzaldua, Gloria. Borderlands / La Frontera: The new mestiza. San Francisco: aunt lute books, 1980.

Butler, Judith. Corpos que importam: Os limites discursivos do "sexo". São Paulo: Crocodilo Edições, 2019.

Darwich, Mahmoud. Na Presença da Ausência. Porto: Flâneur, 2018.

Freire, Paulo. Pedagogia do Oprimido. Rio de Janeiro: Paz e Terra, 1987.

Human Rights Watch. "A Threshold Crossed Israeli Authorities and the Crimes of Apartheid and Persecution". Human Rights Watch. Acesso em 19 de agosto, 2021. https://www.hrw.org/report/2021/04/27/threshold-crossed/israeli-authorities-and-crimes-apartheid-and-persecution.

Jawad, Saleh Abdel. "La política israelí hacia el Pueblo palestino: un "sociocidio". Viento Sur (2006): 15-22.

Lopes, Maria João. "Shahd Wadi queria poder chamar feministas às palestinianas", Público online, acesso em 19 de agosto, 2021, https://www.publico.pt/2010/04/08/jornal/shahd-wadi-queria-poderchamar-feministas-as-palestinianas-19120272.

Margarit, Joan. Para tener casa hay que ganar la guerra. Barcelona: Austral, 2018.

Masalha, Nur. Palestine: a Four Thousand Year History. Londres: Zed Books, 2020.

Pappé, Ilan. A limpeza étnica da Palestina. São Paulo: Sundermann, 2016.

Roy, Arundhati. Azadi: Freedom. Fascism. Fiction. Chicago: Haymarket Books, 2020.

Said, Edward. Orientalism. New York: Vintage, 1978.

Said, Edward. The question of Palestine. New York, Vintage, 1979.

Santos, Boaventura de Sousa. O Futuro começa agora, da pandemia à utopia. Lisboa: Edições 70, 2020 .

Wadi, Shahd. "Feminismos de corpos ocupados: as mulheres palestinianas entre duas resistências". Dissertação de Mestrado, Faculdade de Letras da Universidade de Coimbra, 2009. https://eg.uc.pt/bitstream/10316/13354/1/Tese_mestrado_Shahd\%20Wadi.pdf.

Wadi, Shahd. Corpos na Trouxa: Histórias-artísticas-de-vida de mulheres palestinianas no exílio. Coimbra: Edições Almedina, S.A., 2017.

Wadi, Shahd. "Corpos na Trouxa: Histórias-artísticas-de-vida de mulheres palestinianas no exílio", Cassandra, acesso em 22 de agosto, 2021, https://www.cassandra.pt/heroides-arquivo-vivo/corposna-trouxa. 
Wadi, Shahd. "Nakba", Dicionário Alice, acesso em 22 de agosto, 2021, https://alice.ces.uc.pt/dictionary/?id=23838\&pag=23918\&id_lingua=1\&entry=24419.

Žižek, Slavoj. Violência: seis reflexões laterais. São Paulo: Boitempo, 2014. 